\title{
Why soccer players are smarter than scientists
}

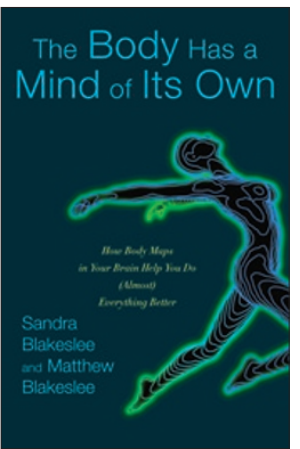

do with our bodies. It's a point that bears repetition. An animal born with normal eyes and a normal brain will grow up functionally blind if it is prevented from moving. Action trains our senses.

Of course, there is always a tradeoff between depth and breadth, and one can sometimes sense the authors' regret at not having more time to explain everything. But they know when to stop themselves. In every chapter, they provide a strong foundation with detailed examples that make a major point: maps are ubiquitous, maps are plastic, maps can go wrong, maps are the basis of our sense of self. To drive home the point, they entertain you with things that you thought you knew (imagery can help you to learn, but imagining and fantasizing are different; you have to know about the stuff that you imagine), things that you do not believe (women are more empathic than men) and things that you could not have imagined (buy yourself a transcutaneous electrical nerve stimulator and try the illusions on pages 34-36).

The book's central point is that because humans are embodied, to understand our experiences, beliefs, actions and cognition, we must consider many maps, each with varying degrees of abstraction that represent or refer back to our bodies. The idea is scientifically cogent, important and, in my view, attractive. We are taught to respect intelligence when it is expressed linguistically, mathematically, musically and even pointlessly (I have chess in mind) as long as it is disembodied. Indeed, comedians and artsy commentators can be as nasty as they like about the intelligence of David Beckham, Ronaldinho and Wayne Rooney, but this book explains why these people are real geniuses, why we should admire and respect their brains.

Elite sports people (especially in team and combat sports) must be able to integrate multiple body maps to read others' movements and intentions, to integrate these with their own body maps and to gauge possible outcomes of their actions. This requires brain plasticity, practice and knowledge; there is, perhaps, more going on in the brains of these sporting elites than in the minds of the media lightweights who mock them. Sporting brains are not the only surprises. Other intellectual outcasts are also given coordinates in the brain's maps of the body. You will find good accounts of the brain basis of auras, out-of-body experiences, why homophobics literally feel the love they hate and why some people crave the amputation of apparently normal limbs.

The book ends with an apology to working scientists for oversimplifications, omissions and possible misrepresentations. I think that the apology is unnecessary. True, one can pick fights with the book. The Mandala concept was unnecessary in my reading, transcranial magnetic stimulation does not really "stun and fatigue" neurons, and women are not really more empathic than men. (Did I mention that already? Sorry, I didn't feel enough men share my rage the first time.) But the subject matter of this book is both difficult and consequential, and if the price for conveying how our brains map our bodies is a few disgruntled scientists, it is a price worth paying. There is only one serious complaint to be made about the book. I understand that it is not directed at primary researchers, but the lack of any guides to further reading is a pity, especially as this book will make you want to know more.

The author is in the Institute of Cognitive Neuroscience

and Department of Psychology, University College London,

17 Queen Square, London WC1N 3AR, UK.

e-mail:v.walsh@ucl.ac.uk 